\title{
Climate Controls on Longshore Sediment Transport
}

\author{
Kristen D. Splinter ${ }^{\mathrm{a}, \mathrm{c}, *}$, Mark A. Davidson $^{\mathrm{b}}$, Aliasghar Golshani ${ }^{\mathrm{a}}$, Rodger \\ Tomlinson $^{\mathrm{a}}$ \\ ${ }^{a}$ Griffith Centre for Coastal Management, Griffith University, Gold Coast Campus, \\ Queensland 4222, Australia \\ ${ }^{b}$ School of Marine Science and Engineering, University of Plymouth, Drake Circus, Plymouth, \\ Devon PL4 8AA, UK \\ ${ }^{c}$ now at: Water Research Laboratory, School of Civil and Environmental Engineering, \\ University of New South Wales, 110 King St, Manly Vale, NSW 2093, Australia
}

\begin{abstract}
Subtle changes in the directional wave climate driven by changes in large scale climate variability have the potential to result in spatial changes (erosion and accretion) of sandy coastlines due to deviations in longshore sediment transport supply. $50+$ years of hindcast offshore directional wave conditions for southeast Queensland, Australia were used to derive yearly wave climates that were input into a spectral wave model to estimate nearshore breaking wave conditions and resulting longshore sediment transport along a $35 \mathrm{~km}$ stretch of sandy coastline. Resulting temporal deviations in net annual longshore transport were smoothed using a 5-year Hamming filter and compared against two climate indices known to influence the Australian climate: the Southern Oscillation Index (SOI) and the Inter-decadal Pacific Oscillation (IPO). During the negative IPO phase (more El Niño like) deviations in estimated transport were significantly correlated to the SOI index at -1 year lag and correlated to the IPO index at +1 year lag. During positive phases of the IPO (more La Niña like) highest correlations were found at 6 year lag (SOI) and -10 year lag (IPO). A linear regression model combining the influence of both indices explained $65 \%$ of the predicted variability in longshore transport during negative phases of the IPO and $48 \%$ of the variance during positive phases of the IPO. During positive phases of the IPO, the SOI index was


shown to dominate model response and may indicate an increase in the influence of the South Pacific Convergence Zone with respect to the wave climate off the east coast of Australia. A model spanning both phases and only considering positive lags (knowledge of past climate indices) explained approximately half of the predicted variability in longshore transport over the entire record length. The results presented here indicate strong links between these large scale climate indices and estimated longshore transport $(0.69 \leq R \leq 0.83)$, such that a simple model derived from knowledge of these indices could be used as a first pass estimate of spatial and temporal variability in longshore sediment transport and resulting large scale coastal evolution.

Keywords:

Longshore transport, Sediment transport, Climate variability, Southern

Oscillation Index, Inter-decadal Pacific Oscillation, Wave clustering, Gold Coast Australia

\section{Introduction}

Understanding the impacts of variations in wave height and wave direction, as well as the timescales of these changes is crucial in predicting future shoreline position. For instance, seasonal scale shoreline evolution has been linked to variations in wave height (e.g. Shepard, 1950; Bascom, 1953; Thom and Hall, 1991). Larger waves, and more frequent storms during the winter months result in beach recession, while calmer conditions encourage shoreline progradation. In many short-term (3 - 5 year) studies, this seasonal variability in wave climate is the key driver of inter-annual shoreline variability. During El Niño-Southern Oscillation (ENSO) events, these seasonal increases in wave heights can also be associated

\footnotetext{
${ }^{*}$ Corresponding author:

Email address: k.splinter@unsw.edu.au (Kristen D. Splinter) Preprint submitted to Continental Shelf Research
} 
with increases in storm frequency, duration, and intensity and changes in mean wave direction (e.g. Ranasinghe et al., 2004; Goodwin, 2005; Hemer et al., 2007; Harley et al., 2010). A number of researchers have reported on the directional changes in storm waves associated with ENSO events and shoreline response, including oscillation, and beach rotation due to changes in the predominant wave energy impacting the coast and the direction of longshore transport (e.g. Ranasinghe et al., 2004; Adams et al., 2008, 2011; Barnard et al., 2011; Harley et al., in press). Along the south-east Australian coast, where waves are predominately from the south-east, La Niña events result in anit-clockwise shift in wave direction, an increase in storms, and on pocket beaches, an anti-clockwise rotation of the beach face as the northern end of beaches erode and the southern end accretes (e.g. Ranasinghe et al., 2004; Harley et al., in press). Similarly, on west coast US beaches, El Niño events result in storm waves approaching more from the south and/or west (anti-clockwise rotation), erosion at the southern ends of beaches and accretion at the north resulting in a general anti-clockwise rotation of the beach (e.g. Adams et al., 2011; Barnard et al., 2011).

Beyond seasonal scale variability in wave height, long term changes in both wave height and in wave direction are predicted under future climate scenarios by a number of researchers(e.g. Hemer et al., 2009, 2010; Ruggiero et al., 2010b). Changes in wave height and wave angle influence the amount of wave energy arriving along the coastline, and in turn, longshore energy flux, currents and longshore sediment transport. Several studies (e.g. Peterson et al., 1990; Ruggiero et al., 2005; Ashton and Murray, 2006a,b; Goodwin et al., 2006; Ruggiero et al., 2010a; Hansen and Barnard, 2010) note that understanding the gradients in longshore transport and sediment budgets may be the most important factor in predicting decadal scale evolution of open coastlines. Cowell et al. (1995) showed that a $1 \%$ deficit in longshore transport sand supply could have the same impact as $0.5 \mathrm{~m}$ sea level rise in terms of shoreline retreat and is therefore an important 
parameter that needs to be considered.

The aim of this paper is to determine the relationship between ENSO-time scale (5-12 years) deviations in the directional wave climate and estimated longshore sediment transport. Timeseries of directional offshore waves were condensed using a data-clustering method to a number of representative annual directional wave climates $\left(H_{s}, T_{p}, \theta\right)$, where $H_{s}$ is significant wave height, $T_{p}$ is peak wave period, and $\theta$ is mean wave direction. These representative annual wave climate parameters (herein referred to as cluster centers) were the input to a standard nearshore spectral wave model to determine nearshore wave conditions at the $10 \mathrm{~m}$ contour for a $35 \mathrm{~km}$ stretch of coastline located along the Gold Coast, Australia (Fig. 1). At six predefined transects, waves were then shoaled and refracted along high resolution bathymetry to determine breaking wave heights, $H_{b}$, and breaking wave angle with respect to the local shore-normal, $\theta_{b}$. Breaking wave conditions were used to provide estimates of wave induced longshore sediment transport by the formulation of Kamphuis (1991). The resulting spatial and temporal variability of annual net longshore transport were compared to two major climate variability indices that significantly influence East Australian climate (Goodwin (2005), Fig. 2): the Inter-decadal Pacific Oscillation (IPO) and the Southern Oscillation Index (SOI). ENSO scale variability is measured via the SOI that is derived from the normalized mean sea level pressure differences between Tahiti and Darwin (Troup, 1965). The IPO index is similar to the Pacific Decadal Oscillation (PDO), however, is Pacific wide and manifests itself symmetrically approximately around the equator. It is measured as the $3 \mathrm{rd}$ Empirical Orthogonal Function of a 13-year lowpass filtered global sea surface temperature projected onto annual data (Folland et al., 1999).

The remainder of the paper is broken down as follows. The study region is briefly described in Section 2. Section 3 summarizes the data used in the present study, including a description of the sediment transport equations and the wave 
clustering method used to describe the annual wave climate. Correlations between climate indices and deviations in longshore transport are presented in Section 4 and a model describing the relationship between the two is developed. Results are further discussed and major findings summarized in Section 5.

\section{Study Area}

\subsection{Geography}

The Gold Coast is located in southeast Queensland, Australia, extending from the New South Wales - Queensland border to the entrance of the Nerang River (Fig. 1). The $35 \mathrm{~km}$ coastline is characterized by fine to medium sand-sized grains $\left(0.2 \mathrm{~mm}<d_{50}<0.3 \mathrm{~mm}\right)$ with a primary dune system. The nearshore morphology is an energetic intermediate beach (Wright and Short, 1984) with a double-barred system (van Enckevort et al., 2004). Both cross-shore and longshore processes affect the temporal evolution of the shoreline. As observed on other wave-dominated coasts, a strong seasonal signal in the shoreline is present (Davidson and Turner, 2009). Net longshore transport for the region is frequently quoted as 500,000 $\mathrm{m}^{3} / \mathrm{yr}$ to the north (Dyson et al., 2002; Patterson, 2007; Castelle et al., 2009), referring to the seminal studies completed by Delft Hydraulics Laboratory (DHL, 1970, 1992). However, spatial and temporal variations in this estimate are present due to spatial variation in wave exposure and sediment supply (Patterson, 2007).

Interspersed along the coast are three natural headlands (Point Danger, Currumbin Rock, and Burleigh Headland) and four river inlets that alter the natural longshore transport of sand. Point Danger, located at the Queensland - New South Wales border shadows the southern end of the coast from the dominant southeasterly wave climate. The rivers may be considered as a modest and localized net sink for sediment and are periodically dredged. Both the Nerang and 
Tweed River entrances have training walls that disrupt the longshore transport such that sand by-passing systems have been installed at both sites. Historical pumping rates vary between $400,000 \mathrm{~m}^{3} / \mathrm{yr}$ and $800,000 \mathrm{~m}^{3} / \mathrm{yr}$ (Patterson, 2007; Castelle et al., 2009). The Tweed River by-passing system transports sand from Letitia Spit, New South Wales (Fig. 1, ETA 08) to several sites between Duranbah Beach and Kirra Point, Queensland, depending on prevailing beach conditions (Dyson et al., 2002; Castelle et al., 2009). The Nerang River bypassing system transports sand from The Spit (ETA 79) to South Stradbroke Island. Rock training walls at Currumbin and Tallebudgera Creeks and groynes at Coolangatta, Kirra, and Palm Beach also impact longshore transport along the coast. An artificial reef is located offshore of Narrowneck at ETA 67 to provide additional shoreline protection and additional surfing amenity (Turner, 2006) . Additionally, most of the coastline is backed by a boulder wall running parallel to the shoreline, limiting shoreward retreat and sediment supply.

\subsection{Wave Climate}

The predominance of southeasterly waves at this site results in a net longshore transport to the north. A more detailed decomposition of the wave field reveals five main wave climate categories. Ground or long-period swell, $G S(T>10 \mathrm{~s})$, is generated in the Southern Ocean and mid-latitudes and occurs year round. It is classified by long periods and low to medium wave heights coming from the south to southeast. These waves infrequently impact the Gold Coast due to their angle of incidence with respect to the coastline (Fig. 1). Medium-period swell, $S(8 \mathrm{~s}<T<10 \mathrm{~s})$, generated in the Tasman Sea also occurs year-round and is the dominant inshore wave climate along the east coast of Australia. During the Australian summer months, local wind seas, $W S(T<8 \mathrm{~s})$, are also present. These are locally generated, short period waves with wave height and direction varying as a function of the strength, duration, and direction of wind and are 
often super-imposed on top of longer-period swell. Two storm categories $\left(H_{s}>3\right.$ $\mathrm{m})$ : East Coast Lows, $E C L$, and tropical cyclones, $T C$, also impact the coast. ECLs are the most frequent, often lasting several days to a week of continued waves, winds, rain, and storm surge. These storms are characterized by their intense low pressure systems and are frequently generated southeast of Australia in the Tasman Sea. They are most common during Australian autumn and winter months (April - August), with June being the most common. TCs are generated in the Coral Sea northeast of Queensland, but rarely propagate as far south as the Gold Coast. TCs that do track this far south (for example Dinah, 1967) bring waves from the E-NE and at times from the E-SE. More commonly, the effects of TCs in northern Queensland are seen as a NE ground swell influencing the coast during the late Australian summer to autumn (January - March).

\section{Data}

\subsection{Waves}

In order to examine the influence of long term climate variability a suitably long directional wave record was needed. The closest wave buoy to the Gold Coast was installed in 1987 and became directional in 2007, and therefore does not contain enough information for this study. Additional local wave buoys at the Tweed River and Brisbane bar were non-directional prior to 1997. Because of this, offshore wave statistics based on the global wind-wave model from the European Centre for Medium-Range Weather Forecasts (ECMWF) 40-year wave Re-Analysis (ERA-40) and interim (ERA-Int) data sets were used. The ERA data sets have been extensively used in previous studies to examine interannual wave climate variability in the Southern Ocean (Hemer et al., 2007, 2009; Harley et al., 2010). Directional wave data $H_{s}, T_{02}$, and $\theta$, where $T_{02}$ is the mean wave period based on the 2nd moment, at 6-hourly intervals was available from 1958 
to present and constituted the longest directional data record in the area.

Caires and Sterl (2005) noted that the original ERA-40 model (1958 - 2001) under-estimated large waves compared to measured data and applied a correction factor to the ERA-40 wave heights (referred to as C-ERA-40). Caires and Sterl $(2001,2005)$ also noted that ERA generated wave periods tended to be slightly over-estimated for swell-dominated sea states, especially in the Pacific Ocean. The two main reasons given were that the coarse grid resolution of the model did not adequately resolve small islands, allowing swell energy to pass through these locations, as well as model limitations that prevented wind-sea growth in the presence of swell. Recently Harley et al. (2010) compared 15 years (1987 2002) of the C-ERA-40 wave heights and 10 years (1992 - 2002) of wave direction to the Sydney wave rider buoy and found good correlation $\left(H_{s}=0.90\right.$ and $\theta=$ $0.77)$ of the annual cycle when westerly $\left(\theta>225^{0}\right)$ waves were removed from the analysis. In general, C-ERA-40 wave heights were over-predicted and ERA-40 wave direction was biased to the south (Figure 4, Harley et al. (2010)). The bias in the westerly waves was attributed to larger fetch lengths in the ECMWF grids compared to the inshore wave rider. For the Gold Coast, the closest co-located ERA grid point $\left(27^{0} \mathrm{~S}, 154.5^{0} \mathrm{E}\right)$ and deep water buoy was to the north of the study site (Fig. 1). The Brisbane wave rider buoy $\left(27.5^{0} \mathrm{~S}, 153.6^{0} \mathrm{E}\right)$ is located in $76 \mathrm{~m}$ of water off the east coast of North Stradbroke Island (Fig. 1) and has been directional since 1997. Analysis of the over-lapping data sets (1997 - 2001) for onshore directed waves $\left(0^{0}<\theta<180^{\circ}\right)$ showed good agreement between data and model $R^{2}: H_{s}=0.83, T_{z}=0.56, \theta=0.71$ ), indicating the ERA data sets are suitable for this study. In all parameters, modeled values were slightly over predicted (bias: $H_{s}=0.005 \mathrm{~m} ; T_{z}=0.68 \mathrm{~s} ; \theta=5.5^{0}$ ).

For the present study, data was extracted from model grid point coordinates $\left(28.5^{0} \mathrm{~S}, 154.5^{0} \mathrm{E}\right)$ located approximately $122 \mathrm{~km}$ southeast of the Gold Coast Seaway (Fig. 1). The southern grid point was chosen due to the dominant 
southerly wave climate of the region. The three ERA data sets available were combined into a single data set herein referred to as the ERA data. Mean wave period and mean wave angle from ERA-40 (1958 - 2001), along with the CERA-40 (1958 - 2001) wave heights were combined with the ERA-Int (2002 present) data. Overlapping time series between the initiation of the ERA-Int re-analysis and the C-ERA-40 data sets (1989 - 2001) were used to determine a non-linear correction factor for the ERA-Int wave heights using a Generalized Additive Model (GAM) technique. Mean wave period from the ERA data set was transformed to peak wave period based on the method of Paik and Thayamballi (2007, p.106) assuming a JONSWAP $(\gamma=3.3)$ spectrum (Hasselmann et al., 1976).

A data clustering method based on the work of Bagirov (2008) and the distance function of Dagnelie (1975) was used to condense the annual wave data into a representative number of data points based on their cluster centers, $x_{j}=\left(\bar{H}_{s}, \bar{T}_{p}, \bar{\theta}\right)_{j}$, where $\overline{()}$ indicates the mean of all data belonging to that cluster. For each iteration, $k$, every data point $\left(a_{i}=\left(H_{s_{i}}, T_{p_{i}}, \theta_{i}\right)\right)$ was assumed a possible centroid of the next cluster, $y_{k}$. Data points were assigned to clusters based on minimization of the distance matrix:

$$
\psi_{k}(X, w)=\frac{1}{m} \sum_{i=1}^{m} \sum_{j=1}^{k} w_{i j}\left\|x_{j}-a_{i}\right\|^{2},
$$

where

$$
X=\left(x_{1}, x_{2}, \ldots, x_{k}\right) \in \mathbb{R}^{n \times k}
$$

is the vector of all cluster centers, $x_{j}, m$ is the total number of data points considered in $\mathbb{R}^{n}$, the real-valued $n$-dimensional space, $w_{i j}$ is a weighting function that was equal to 1 if data point, $a_{i}$, was within cluster $j$, and 0 if it lied outside. 
The distance function has been used in previous studies to condense wave climates (Butel et al., 2002; Abadie et al., 2006; Bertin et al., 2008) and applied in longshore transport studies (Abadie et al., 2006; Bertin et al., 2008) along the French coast. WhileAbadie et al. (2006) used a distance function based on $(H, T$, $\theta$ ), Bertin et al. (2008) found better agreement between modeled and measured longshore transport estimates when their data clustering criteria was a function of $\left(H_{s}^{2}, T, \theta\right)$. Therefore, the generalized distance equation used in the present study was:

$$
\left\|x_{j}-a_{i}\right\|=\sqrt{\frac{\left(H_{s, j}^{2}-H_{s, i}^{2}\right)^{2}}{\sigma_{H_{s}^{2}}^{2}}+\frac{\left(T_{p, j}-T_{p, i}\right)^{2}}{\sigma_{T_{p}}^{2}}+\frac{\left(\theta_{j}-\theta_{i}\right)^{2}}{\sigma_{\theta}^{2}}}
$$

where $\sigma^{2}$ is the variance of the associated variable. A detailed description of the clustering technique can be found in Bagirov (2008).

The benefit of this method over those described in Butel et al. (2002); Abadie et al. (2006); Bertin et al. (2008) was that a minimum tolerance for changes, $\epsilon$, in cluster centers, $x_{j}$, rather than the number of clusters/bins, $k$, was chosen, therefore the variance of the data determined the number of clusters for each year. For this study $\epsilon=0.005$, which resulted in a mean number of wave clusters per year of 15.54 with a standard deviation of 2.8. The minimum number of classes was 9 (in 1971, 2003, 2006) and the maximum was 20 (in 1985). One key criteria of any clustering method is to adequately represent the extreme events which have been shown to significantly impact on seasonal shoreline behavior (e.g. Barnard et al., 2011). For the 50+ year record, the cluster representing the highest wave heights (mean $=4.37 \mathrm{~m}$, std $=0.68 \mathrm{~m}$ ) accounted for on average $3.45 \%(\operatorname{std}=2.21 \%)$ of the waves for a given year. Therefore the clustering method with a distance function based on $H_{s}^{2}$ adequately isolated the extreme events. By comparison, a distance function based on $H_{s}$ resulted in an average of 15.92 clusters/year $(\operatorname{std}=3.5)$. The mean highest wave heights was slightly 
lower $(4.29 \mathrm{~m}$, std $=0.66 \mathrm{~m})$ and accounted for on average slightly more of the waves, mean $=3.83 \%(\operatorname{std}=2.47 \%)$ for a given year.

A summary of the wave climate is given in Table 1 and in Figure 3. Wave angles $(\theta)>185^{\circ} \mathrm{N}$ were removed from further analysis as they represented offshore directed waves. Figure 3 clearly shows the inter-annual, as well as longterm trends in wave climate for southeast Queensland, Australia. Also worth noting is the shift of wave clusters from wind sea $\left(T_{p}<8\right.$ s) to swell $\left(8<T_{p}<10\right.$ s) indicating a shift to longer period waves.

\subsection{Estimated Longshore Sediment Transport}

Breaking wave height, $H_{b}(\mathrm{~m})$, peak period, $T_{p}(\mathrm{~s})$, and breaking wave angle with respect to the shore-normal, $\theta_{b}$ (degrees), all contribute to the longshore current (and in turn longshore sediment transport) through the transfer of momentum from the breaking waves to the water column. Breaking wave parameters were calculated using a two-step method. First, nearshore wave conditions (10 $\mathrm{m}$ water depth) at six sites along the Gold Coast were modeled using the MIKE 21 Spectral Wave (SW) model. MIKE 21 SW has been previously used along south-east Queensland to estimate storm surge and wave statistics during several extreme events (e.g. Golshani et al., 2012) with reasonable success. Comparisons of wave statistics against the Gold Coast buoy for the Fraser ECL had rms errors in $H_{s}$ of $0.67 \mathrm{~m}, T_{p}$ of $1.6 \mathrm{~s}$, and $\theta$ of 18 degrees. Within the scope of the current work, comparisons between MIKE 21 output at ETA 67 (18m of water) and the Gold Coast buoy for 1999 had rms errors in $H_{s}=0.33 \mathrm{~m}$, and in $T_{p}=1.96 \mathrm{~s}$. (Gold Coast buoy was non-directional prior to 2007).

Results from the wave clustering model were used to force open boundaries of the model domain. To account for the degree of directional spreading, the directional standard deviation, DSD (see MIKE $21 \mathrm{SW}$ user manual, pg. 83), was calculated for each wave cluster based on the waves that comprised that cluster. 
Therefore, wave clusters that were defined over a large range of wave directions spread the energy accordingly and narrow-banded wave clusters concentrated energy into a small number of directional bins. The second step involved propagating the modeled output from MIKE $21 \mathrm{SW}$ along high resolution bathymetry at each of the six transects from the $10 \mathrm{~m}$ contour to the breakpoint based on linear theory and Snell's Law to determine breaking wave height, $H_{b}$, and breaking wave angle with respect to shore-normal, $\theta_{b}$. The breaking criteria was set to $\gamma=H_{r m s} / h=0.42$ (e.g. Komar, 1974).

For the purpose of this study the widely used formulation of Kamphuis (1991) was adopted to estimate longshore transport:

$$
Q\left(m^{3} / s\right)=\frac{0.0013 \rho_{w}}{\left(\rho_{s}-\rho_{w}\right)(1-p)} \frac{H_{b}^{3}}{T_{p}}\left(\frac{H_{b}}{L_{o}}\right)^{-1.25} \tan \alpha_{b}^{0.75}\left(\frac{H_{b}}{d_{50}}\right)^{0.25} \sin ^{0.6}\left(2 \theta_{b}\right)
$$

where $\rho_{s}$ and $\rho_{w}$ are the density of sediment $\left(2650 \mathrm{~kg} / \mathrm{m}^{3}\right)$ and water $(1025$ $\left.\mathrm{kg} / \mathrm{m}^{3}\right)$, respectively, $p$ is the sediment porosity $(0.4), L_{o}(\mathrm{~m})$ is the deep water wavelength, $d_{50}(0.22 \mathrm{~mm})$ is the median grain size diameter of sediment, and $\tan \alpha_{b}$ is the mean beach slope. The Kamphuis equation was chosen as it accounts for beach slope and has been successfully used on the Gold Coast in previous studies (e.g. Patterson, 2007). Here beach slope was defined as the time averaged beach slope between the $0 \mathrm{~m}$ and $-5 \mathrm{~m}$ AHD depth contour (representative of the active surf zone). As the focus of this research was on the influence of changes in offshore wave conditions on estimated longshore transport rates, temporal variations in beach slope were not considered.

Time-averaged (1958 - 2009) estimated longshore transport rates (net and gross) for the six study sites are presented in Figure 5. Estimates for the more exposed areas of the study area (ETA 08, ETA 58-79, Fig. 1) are in general agreement with previously published estimates of longshore transport in the area 
(DHL, 1970, 1992; Patterson, 2007). Using time series buoy data from the Brisbane wave recorder, Patterson (2007) estimated the annual net longshore sand transport to be $635,500 \mathrm{~m}^{3} / \mathrm{yr}$ for the Spit ( ETA79) and $540,000 \mathrm{~m}^{3} / \mathrm{yr}$ for Narrowneck ( ETA 67). By comparison, the wave clustering method forced by ERA data estimated transport at these 2 sites to be $715,000 \mathrm{~m}^{3} / \mathrm{yr}$ and 546,000 $\mathrm{m}^{3} / \mathrm{yr}$, respectively. Differences in estimated transport at Narrowneck for the two methods are negligible (difference of $6,000 \mathrm{~m}^{3} / \mathrm{yr}$ ), however, the transport estimates for the Spit presented here are larger using the clustering method than reported by Patterson (2007). Slight variations in the shoreline orientation, sediment diameter, source of wave data and time series versus wave clustering can account for the differences between the two results. Comparisons of estimated longshore transport for 1991 and 1999 based on the offshore ERA wave data and MIKE 21 model with offshore wave conditions based on the clustering method described here, as well as that of Abadie et al. (2006) and full time series runs $(D S D=20$ degrees, Callaghan (2005)) are presented in Table 2. At the more sheltered sites (ETA 32 and 43) transport was under-estimated by $10-30 \%$ based on the clustering methods, while at ETA 58 and ETA 79 the transport was overestimated by $9-49 \%$. ETA 67 showed the best comparison (error between 1 and $-7 \%)$.

This confirms that the wave clustering methodology appears to be an appropriate representation of the offshore wave climate. Annual net longshore transport rates for each of the sites are presented in Figure 6. Clear inter-annual variability is evident, in particular the storm years of 1967, 1973-74, and 1999 have significant longshore transport predicted. Annual net transport rates (1958 - 2009) were also smoothed using a 5-year Hamming window and highlight long term trends, as well as oscillatory cycles in estimated transport. 


\section{Results}

Analysis of the wave clustering results show several interesting trends in the ERA data sets. First, the percent occurrence of storm waves shows an increasing trend through the IPO phases (Fig. 4). During the negative phase of the IPO (1958 - 1976), the SOI index was on average more positive, and vice versa during the positive IPO phase (1977 - 1999), therefore the magnitude of the cumulative SOI (or IPO) index may be a good indicator of storm activity off the east coast of Australia. On shorter time scales, La Niña phases coincide with more storms (Fig. 4) and is in agreement with previous results for this region (Ranasinghe et al., 2004; You and Lord, 2008; Harley et al., 2010).

\subsection{Correlation Between Net Longshore Transport and Climate Indices}

Of particular interest within the context of this study is the inter-annual variability in estimated net longshore transport, expressed as deviations about a time mean transport rate, $\Delta Q(t)=Q_{N E T}(t)-\overline{Q_{N E T}}$, where $\overline{Q_{N E T}}$ is the time mean net transport at each of the six transects. Lagged cross-correlations between indices (SOI and IPO, Fig. 2) and $\Delta Q$ were performed at each transect. Large inter-annual variability may be linked to additional factors not captured in the SOI and IPO, therefore cross-correlations between the 5-year smoothed transport and 5-year smoothed indices were also performed. The smoothing also represents the impact of cumulative effects of prolonged positive or negative values of an index (Fig. 4) and helps account for the lag between shifts in indices and shoreline response previously observed (e.g. Ranasinghe et al. (2004); Harley et al. (2010)). The analysis was separated into distinct IPO phases to determine if phase changes influenced overall correlations. Table 3 summarizes the results, providing the maximum significant correlation, $R$, (and associated lag in years, $\tau$ ) for each of the time periods. Positive lags indicate the indices leads the predicted transport. 
Correlations between $\Delta Q$ and the climate indices for the negative IPO phases (1958 - 1976 and 2000 - 2009) were not significant. The short record length for 2000 - 2009 limited any conclusions from this time period. However, for the positive IPO phase (1977 - 1999) significant correlations between $\Delta Q$ and both the SOI (most common lag $=0$ years) and IPO $(\tau=-4,-10,-14)$ were observed at all transects. The smoothed data (i.e. $\mathrm{SOI}_{5}$ ) was significantly correlated for both phases of the IPO. On average, during the negative IPO phase (1958 - 1976), $\Delta Q_{5}$ was significantly negatively correlated with the SOI index at $\tau=-1$, while during the positive IPO phase $(1977$ - 1999) a slight shift to $\tau=0$ was observed (more significant lags were found at 6 and 9 years at some sites, Table 3 ). The relationship between IPO and $\Delta Q_{5}$ was less obvious. During the negative phase of IPO, significant positive correlations between $\Delta Q_{5}$ and IPO were observed at $\tau=+1$ and negative correlations at $\tau=+9$ and +10 years. During the positive phase, $\Delta Q_{5}$ was positively correlated at most sites around $\tau=-14$ and -10 years and at $\tau=+10$ and +11 years.

\subsection{Deviations in Net Longshore Transport Explained by Climate Indices}

Based on the significant correlations found between the two smoothed individual climate indices and estimated deviations in longshore transport, a simple lagged-correlation regression model was developed to estimate $\Delta Q_{5}$ based on the combined effect of both 5-year smoothed climate indices:

$$
\Delta \hat{Q}_{5}= \begin{cases}\beta_{0}+\beta_{1} S O I_{5}\left(\tau_{1}\right)+\beta_{2} I P O_{5}\left(\tau_{2}\right) & \text { IPO }<0, \\ \beta_{0}+\beta_{1} S O I_{5}\left(\tau_{3}\right)+\beta_{2} I P O_{5}\left(\tau_{4}\right) & \text { IPO }>0\end{cases}
$$

where lags, $\tau$, were chosen based on the highest number of significant correlations at a given lag. Considering the variability in the SOI term dominates the signal variability and also contains a low-frequency modulation similar to that of the IPO index (Fig. 2), an extra sum of squares (or partial F-test) test was used 
to determine if the IPO index significantly improved the results over the simple 1-parameter SOI model:

$$
\Delta \hat{Q}_{5}= \begin{cases}\beta_{0}+\beta_{1} S O I_{5}\left(\tau_{1}\right) & \text { IPO }<0, \\ \beta_{0}+\beta_{1} S O I_{5}\left(\tau_{3}\right) & \text { IPO }>0,\end{cases}
$$

For the negative IPO phase, lags at $\tau_{1}=[-7,-1,11]$ and $\tau_{2}=[1,2]$ were compared. The highest model skill was found using $\tau_{1}=-1$ and $\tau_{2}=2$ (mean $R^{2}=0.65$, Fig. 7 ), with the second highest using $\tau_{1}=-1$ and $\tau_{2}=1$ (mean $R^{2}=0.54$ ). The model had significant regression skill (at the $95 \%$ level) at all sites, and only 1 site did not show a statistically significant improvement over the simpler 1-parameter SOI model (Table 4) indicating the interaction between both indices was important during the negative IPO phase.

During the positive IPO phase, models based on $\tau_{3}=[0,6]$ and $\tau_{4}=[-10,-9]$ were compared. The highest model skill was found using $\tau_{3}=6$ and $\tau_{4}=-10$ (mean $R^{2}=0.48$, Fig. 8), with the second highest using $\tau_{3}=6$ and $\tau_{2}=-9$ (mean $R^{2}=0.48$, Table 5 ). The model had significant regression skill at all 6 sites, however only 2 sites had a statistically significant improvement over the simpler 1-parameter SOI model. This suggests that during the positive phase of the IPO the directional wave climate off the east coast of Australia is primarily influenced by variations in the SOI rather than the interaction of both indices. With $\tau_{3}=0$, mean $R^{2}$ was reduced to 0.30 and the model had significant skill at 3 of the sites ( 1 of which had a statistically significant improvement of the 1-parameter model).

A model that could be used to predict deviations in longshore transport over all time scales would be ideal. To test this, only positive lags (knowledge of current and past climate indices) were considered in the lagged correlation model for the entire data record (1958 - 2009). A model based on $\tau_{S O I}=0$ and $\tau_{I P O}$ 
$=4$ explained the largest percent of variance (mean $R^{2}=0.49$, Fig. 9). The model showed significant skill (95\% level) at all sites and the 2-parameter model statistically improved the results over the simpler 1-parameter model at all sites (see Table 6). In general, larger coefficients were associated with the more exposed sites.

\section{Discussion and Conclusions}

A linear regression model based on the relationship between climate indices and deviations and transport was presented in Section 4.2. During negative phases of the IPO (more La Niña like) both SOI and IPO significantly contributed to the variance explained in deviations of net sediment transport along the Gold Coast, Australia. However, during positive phases of the IPO, the SOI index accounted for a significant portion of explained variability and knowledge of the IPO index improved model skill at only two sites. A possible explanation for this can be found in the location and variability of the South Pacific Convergence Zone, SPCZ, (Salinger et al., 2001; Folland et al., 2002). The SPCZ is located in the south Pacific around the French Polynesian islands $\left(0^{0}-30^{0} \mathrm{~S}, 150^{0} \mathrm{E}-90^{\circ} \mathrm{W}\right)$ and is a key feature influencing the climate around the southern hemisphere. Its location has been shown to be modulated by both the SOI and IPO (Salinger et al., 2001; Folland et al., 2002). When the IPO is in its negative phase, the mean position of the SPCZ is shifted to the south-west (closer to Australia) and is furthest south-west for La Niña events during this phase. Additionally when the SPCZ is west of $140^{\circ} \mathrm{W}$ both indices influence its latitude. Conversely, during positive IPO phases the SPCZ moves to the north-east and is furthest northeast for El Niño events of this phase. When the SPCZ is east of $140^{0} \mathrm{~W}$ only the SOI significantly influences its position. These observations agree with our findings that during negative phases of the IPO when both indices are shown to 
influence the location of the SPCZ a two-parameter model based on both indices significantly improves our estimates on deviations in sediment transport. The same is seen for positive phases when the location of the SPCZ is influenced more by the SOI index we find that including the IPO index in our model does not significantly improve our results. A general decrease in variance explained using the model is also observed during the positive phase of the IPO. These observations indicate that the wave climate off southeast Queensland, Australia may be more influenced by the SPCZ (and other impacts of SOI) when the SPCZ is closer to Australia, while when the SPCZ is furthest north-east, the wave climate in the Tasman Sea may also modulated by other climatic variables, such as the Southern Annular Mode, that were not examined in the present paper.

Results presented here for the positive IPO phase (1977 - 1999 ) qualitatively agree with observed beach rotation and shoreline variability for a long-term data set (1976 - 2010) at Collaroy-Narrabeen, NSW (Harley et al., in press). Both Ranasinghe et al. (2004) and Harley et al. (in press) found an anti-clockwise rotation of the beach during positive SOI phases as wave energy shifted counterclockwise from south-south east to south-east/east. Similarly, the regression coefficients (Table 5 ) for the SOI index were positive over this same phase, indicating increases in SOI would drive more positive (southerly) deviations in transport.

In summary, a new wave clustering method was developed in order to examine the temporal links between climate variability (measured via the SOI and IPO indices) and deviations in longshore transport for a $35 \mathrm{~km}$ section of coast along the southeastern coast of Queensland, Australia. Using the ERA wave model output as offshore wave conditions, yearly wave climates were derived and subsequently shoaled and refracted into the breakpoint to determine longshore transport using the formulation of Kamphuis (1991). Estimates of long term average net transport rates for the northern Gold Coast were in good agreement with previously published results. However, considerable spatial and temporal variability 
in longshore transport was predicted. Deviations in net longshore transport were significantly correlated to both indices. Using the 5-year smoothed data, deviations in net transport were significantly correlated to the SOI (IPO) index at the $-1(1)$ and -7 year lag during the negative phases of the IPO. During negative phases of the IPO both the SOI and IPO indices were shown to significantly influence deviations in net sediment transport and a lagged linear regression model based on these two parameters was able to explain $65 \%$ of the predicted variance. During positive phases of the IPO the model explained on average $48 \%$ of the predicted variance, however, results were not significantly (at the $95 \%$ level) improved over the 1-parameter (SOI) model. Over the entire data record (1958 - 2009), significant correlations between the SOI (IPO) index and deviations in predicted longshore transport were found at 0 (4) year lag. It was found that the linear 2-parameter model based on these climate indices alone could explain $49 \%$ (significant at the $95 \%$ level) of the predicted variation in the smoothed longshore transport. These results indicate strong links between these large scale climate indices and deviations in estimated longshore transport $(0.69 \leq R \leq 0.83)$, such that a simple model derived from knowledge of these indices could be used as a first pass estimate of spatial and temporal variability in longshore sediment transport and resulting large scale coastal evolution.

\section{Acknowledgements}

The authors wish to thank A. Sterl (KNMI) for generously providing the C-ERA-40 data used in this study. The authors also wish to extend their appreciation to I.L. Turner for pre-reviewing this manuscript and to P. Barnard and the anonymous reviewer for their insightful feedback that improved this manuscript. K.S. also wishes to thank R. Butel for his initial discussions on the wave clustering methodology and to R. Richards for his help with GAM models. Funding for 
this work was provided by the Queensland Government and Griffith University as part of the Future Coastlines Smart State Project.

\section{References}

Abadie, S., Butel, R., Mauriel, S., Morichon, D., Dupuis, H., 2006. Wave climate and longshore drift on the South Aquitaine coast. Continental Shelf Research 26, 1924-1939.

Adams, P.N., Inman, D.L., Graham, N.E., 2008. Southern California deep-water wave climate: characterization and application to coastal processes. Journal of Coastal Research 24, 10221035 .

Adams, P.N., Inman, D.L., Lovering, J.L., 2011. Effects of climate change and wave direction on longshore sediment transport patterns in Southern California. Climatic Change 109, S211S228.

Ashton, A.D., Murray, A.B., 2006a. High-angle wave instability and emergent shoreline shapes: 1. modeling of sand waves, flying spits, and capes. Journal of Geophysical Research 111.

Ashton, A.D., Murray, A.B., 2006b. High-angle wave instability and emergent shoreline shapes: 2. wave climate analysis and comparison to nature. Journal of Geophysical Research 111.

Bagirov, A.M., 2008. Modified global k-means algorithm for minimum sum-of-squares clustering problems. Pattern Recognition 41, 3192-3199.

Barnard, P.L., Allan, J., Hansen, J.E., Kaminsky, G.M., Ruggiero, P., Doria, A., 2011. The impact of the 2009-10 El-Niño Modoki on U.S. West Coast beaches. Geophysical Research Letters 38.

Bascom, W.H., 1953. Characteristics of natural beaches, in: ASCE (Ed.), Proc. 4th International Conference on Coastal Engineering, pp. 163-180.

Bertin, X., Castelle, B., Chaumillon, E., Butel, R., Quique, R., 2008. Longshore transport estimation and inter-annual variability at a high-energy dissipative beach: St. Trojan beach, SW Oleron Island, France. Continental Shelf Research 28, 1316-1332.

Butel, R., Dupuis, H., Bonneton, P., 2002. Spatial variability of wave conditions on the French Atlantic coast using in-situ data, in: Proceedings of the International Coastal Symposium, Journal of Coastal Research, pp. 96-108.

Caires, S., Sterl, A., 2001. Comparative assessment of era-40 ocean wave product, in: Proceedings of the ECMWF Workshop on Re-analysis, ERA-40 Proj. Rep. Ser., European Centre for Medium-Range Weather Forecasts, Reading, UK. pp. 357-372.

Caires, S., Sterl, A., 2005. A new nonparametric method to correct model data: Application 
to significant wave height from the ERA-40 re-analysis. Journal of Atmospheric and Oceanic Technology 22, 443-459.

Callaghan, D.P., 2005. Issues at the frontiers of coastal morphodynamics modelling. Ph.D. thesis. The University of Queensland. Brisbane, QLD, Australia.

Castelle, B., Turner, I.L., Bertin, X., Tomlinson, R., 2009. Beach nourishment at coolangatta bay over the period 1987-2005. Coastal Engineering 56, 940-950.

Cowell, P., Roy, P., Jones, R., 1995. Simulation of large-scale coastal change using a morphological behaviour model. Marine Geology 126, 45-61.

Dagnelie, P., 1975. Analyse statistique a plusieurs variables. Les Presses agronomiques de Gemloux, deffusion Vander-Oyez, 362.

Davidson, M.A., Turner, I.L., 2009. A behavioral template beach profile model for predicting seasonal to interannual shoreline evolution. Journal of Geophysical Research 114, F01020.

DHL, 1970. Gold Coast, Queensland, Australia - Coastal Erosion and Related Problems. Technical Report R257. Delft Hydraulics Laboratory.

DHL, 1992. Southern Gold Coast Littoral Sand Supply. Technical Report H85. Delft Hydraulics Laboratory.

Dyson, A., Lawson, S., Victory, S., Boswood, P., Mahon, B., Trucchi, L., Cummings, P., 2002. Tweed river entrance sand bypassing project post-commissioning coastal behaviour, in: Proc. 28th International Conference on Coastal Engineering, ASCE, Cardiff, Wales. pp. 3478-3752. van Enckevort, I., Ruessink, B., Coco, G., Suzuki, K., Turner, I., Plant, N., Holman, R.A., 2004. Observations of nearshore crescentic sandbars. Journal of Geophysical Research 109, C06028.

Folland, C.K., Parker, D.E., Colman, A., Washington, R., 1999. Beyond El Niño: Decadal and Interdecadal Climate Variability. Springer-Verlag, Berlin. chapter Large scale modes of ocean surface temperature since the late nineteenth century. pp. 73-102.

Folland, C.K., Renwick, J.A., Salinger, M.J., Mullan, A.B., 2002. Relative influences of the Interdecadal Pacific Oscillation and ENSO on the South Pacific Convergence Zone. Geophysical Research Letters 29, 1643.

Golshani, A., Stuart, G., Tomlinson, R., 2012. Storm surge modeling of fraser east coast low event in south east queensland, australia, in: 8th INTERNATIONAL CONFERENCE ON COASTAL AND PORT ENGINEERING IN DEVELOPING COUNTRIES, IIT Madras, Chennai, INDIA. pp. 158-168.

Goodwin, I.D., 2005. A mid-shelf, mean wave direction climatology for southeastern Australia, and its relationship to the El-Niño-Southern Oscillation since 1878 AD. International Journal of Climatology 25, 1715-1729. 
Goodwin, I.D., Stables, M.A., Olley, J.M., 2006. Wave climate, sand budget and shoreline alignment evolution of the Iluka-Woody Bay sand barrier, northern New South Wales, Australia, since 3000 yr BP. Marine Geology 226, 127-144.

Hansen, J.E., Barnard, P.L., 2010. Sub-weekly to interannual variability of a high-energy shoreline. Coastal Engineering 57, 959-972.

Harley, M.D., Turner, I.L., Short, A.D., Ranasinghe, R., 2010. Interannual variability and controls of the Sydney wave climate. International Journal of Climatology 30, 1322-1335.

Harley, M.D., Turner, I.L., Short, A.D., Ranasinghe, R., in press. A re-evaluation of coastal embayment rotation: the dominance of cross-shore versus alongshore sediment transport processes, Collaroy-Narrabeen Beach, SE Australia. Journal of Geophysical Research .

Hasselmann, K., Ross, B., Muller, P., Sell, W., 1976. A parametric wave prediction model. Journal of Physical Oceanography 6, 200-228.

Hemer, M., Church, J., Hunter, J., 2007. Waves and climate on the Australian coast, in: Proceedings of the 9th International Coastal Symposium, Journal of Coastal Research SI 50. pp. $432-437$.

Hemer, M., McInnis, K., Ranasinghe, R., 2010. Projected future wave climate along Australia's eastern margin, in: Day, K.A. (Ed.), Proceedings of the Australian Wind Waves Research Science Symposium, 19-20 May 2010, Gold Coast, Queensland, Australia, The Centre for Australian Weather and Climate Research. pp. 46-49.

Hemer, M.A., Church, J.A., Hunter, J.R., 2009. Variability and trends in the directional wave climate of the southern hemisphere. International Journal Of Climatology 30, 475-491.

Kamphuis, J., 1991. Alongshore sediment transport rate. Journal of Waterway, Port, Coastal, and Ocean Engineering 117, 624-640.

Komar, P.D., 1974. Beach Processes and Sedimentation. Prentice-Hall, Englewood Cliffs, N.J. Paik, J.K., Thayamballi, A.K., 2007. Ship-Shaped Offshore Installations: Design, Building, and Operation. Cambridge University Press.

Patterson, D., 2007. Sand transport and shoreline evolution, Northern Gold Coast, Australia, in: Proceedings of the 9th International Coastal Symposium, Journal of Coastal Research SI 50. pp. $147-151$.

Peterson, C.D., Jackson, P.L., O’Neil, D.J., Rosenfield, C.L., Kimerling, A.J., 1990. Littoral cell response to interannual climatic forcing 1983-1987 on the central Oregon coast, USA. Journal of Coastal Research 6, 87-110.

Ranasinghe, R., McLoughlin, R., Short, A., Symonds, G., 2004. The Southern Oscillation Index, wave climate, and beach rotation. Marine Geology 204, 273-287. 
Ruggiero, P., Buijsman, M., Kaminsky, G.M., Gelfenbaum, G., 2010a. Modeling the effects of wave climate and sediment supply variability on large-scale shoreline change. Marine Geology $273,127-140$.

Ruggiero, P., Kaminsky, G.A., Gelfenbaum, G., Voigt, B., 2005. Seasonal to interannual morphodynamics along a high-energy dissipative littoral cell. Journal of Coastal Research 21, $553-578$

Ruggiero, P., Komar, P.D., Allan, J.C., 2010b. Increasing wave heights and extreme value projections: The wave climate of the U.S. Pacific Northwest. Coastal Engineering 57, 539552 .

Salinger, M.J., Renwick, J.A., Mullan, A.B., 2001. Interdecadal Pacific Oscillation and the South Pacific climate. International Journal of Climatology 21, 1705-1721.

Shepard, F.P., 1950. Beach cycles in southern California. Tech. memo. 20. USACE, Beach Erosion Board.

Thom, B.G., Hall, W., 1991. Behaviour of beach profiles during accretion and erosion dominated periods. Earth surface processes and landforms 16, 113-127.

Troup, A.J., 1965. The Southern Oscillation. Quarterly Journal of the Royal Meterological Society $91,490-506$.

Turner, I.L., 2006. Discriminating modes of shoreline response to offshore-detached structures. Journal of Waterway Port Coastal and Ocean Engineering 132, 180-191.

Wright, L.D., Short, A.D., 1984. Morphodynamic variability of surf zones and beaches: A synthesis. Marine Geology 56, 93-118.

You, Z.J., Lord, D., 2008. Influence of the El Niño - Southern Oscillation on NSW coastal storm severity. Journal of Coastal Research 24, 203-207. 
Table 1: Summary of wave clustering statistics based on offshore ERA data sets.

Table 2: Comparison of estimated longshore transport $\left(10^{5} \mathrm{~m}^{3} / \mathrm{yr}\right)$ using the clustering method of Abadie et al. (2006) with $H$, and of Bertin et al. (2008) with $H^{2}$, and timeseries method.

Table 3: Correlation analysis between deviations in $Q_{N E T}\left(\Delta Q\left(10^{5} \mathrm{~m}^{3} / \mathrm{yr}\right)\right)$ and SOI and IPO indices. Values indicate the maximum significant correlation $(R)$ and lag $(\tau$, years). Note that other significant lags can (and do) exist. Positive lags indicate Index leads changes in $\Delta Q . \mathrm{N} / \mathrm{A}$ indicates no significant ( $95 \%$ level) correlation was found. 5-year smoothing (i.e. $S O I_{5}$ ) was done using a Hamming window.

Table 4: Regression coefficients for the negative phase of the IPO $(1958-1976)$ with $\tau_{1}=-1$ and $\tau_{2}=2$. Model skill was based on percent of observed variance explained, i.e. $R^{2} .{ }^{*}$ Indicates 2-parameter model had significant skill at the $95 \%$ level. \# Indicates the 2-parameter model significantly improved the model skill over the 1-parameter version.

Table 5: Regression coefficients for the positive phase of the IPO $(1977-1999)$ with $\tau_{3}=6$ and $\tau_{4}=-10 .{ }^{*}$ Indicates 2-parameter model had significant skill at the $95 \%$ level. $\#$ Indicates the 2-parameter model significantly improved the model skill over the 1-parameter version.

Table 6: Regression coefficients for entire data set with $\tau_{S O I}=0$ and $\tau_{I P O}=4 .{ }^{*}$ Indicates 2-parameter model had significant skill at the $95 \%$ level. \# Indicates the 2-parameter model significantly improved the model skill over the 1-parameter version.

Figure 1: Southeast Queensland map with location of the 2 closest ERA wave model points and Brisbane buoy along with the six locations (eta lines) where longshore transport was estimated.

Figure 2: SOI and IPO indices for study period. Note that the axis for the IPO (right hand side) is reversed.

Figure 3: Breakdown of wave clustering by year. Due to the offshore location of the grid point, it is possible for the model to generate offshore directed waves by local wind generation. As offshore directed waves will not impact the coast, these are not included and account for the white space amounting to $100 \%$.

Figure 4: Percent occurrence of wave clusters defined as a storm $\left(H_{s} \geq 3 \mathrm{~m}\right)$. Of particular interest is the almost identical linear increasing trend in number of storms over the 2 IPO phases (1958 - 1976 and 1977 - 1999). The most recent IPO phase shows a much larger trend, however, with such a short data record, inter-annual variability likely dominates this signal. 
Figure 5: Mean longshore transport rates $\left(10^{5} \mathrm{~m}^{3} / \mathrm{yr}\right)$ using Kamphuis (1991) for study period 1958 - 2009. Left to right are the six sites (south to north). Included are the time mean southerly (blue bars), northerly (red bars), and net (green bars) yearly transport rates.

Figure 6: Yearly net longshore transport $\left(10^{5} \mathrm{~m}^{3} / \mathrm{yr}\right)$ estimates with time using Kamphuis (1991). Negative values indicate transport to the north. Top to bottom are the six sites (north to south). The y-axis $\left(Q_{N E T}\right)$ is kept constant to show inter-site variability. Solid bars represent the net yearly transport, while the thin line represents the 5 -year smoothed values.

Figure 7: Lagged-regression model for negative phase of the IPO (1958 - 1976) with $\tau_{1}=-1$ and $\tau_{2}=2$. Black lines are deviations in net longshore transport estimated from Kamphuis (1991). Grey lines are $\Delta Q_{5}$ estimated using equation 5.

Figure 8: Lagged-regression model for positive phase of the IPO $(1977-1999)$ with $\tau_{3}=6$ and $\tau_{4}=-10$. Black lines are deviations in net longshore transport estimated from Kamphuis (1991). Grey lines are $\Delta Q_{5}$ estimated using equation 5.

Figure 9: Lagged-regression model for entire record length with $\tau_{S O I}=0$ and $\tau_{I P O}=4$. Black lines are deviations in net longshore transport estimated from Kamphuis (1991). Grey lines are $\Delta Q_{5}$ estimated using equation 5 . 